Article

\title{
Optimized Estimation of Leaf Mass per Area with a 3D Matrix of Vegetation Indices
}

\author{
Yuwen Chen ${ }^{1}$, Jia Sun ${ }^{1,2, *}$, Lunche Wang ${ }^{1}{ }^{\mathbb{D}}$, Shuo Shi ${ }^{3}$, Wei Gong ${ }^{3}$, Shaoqiang Wang ${ }^{1}$ and Torbern Tagesson ${ }^{2} \mathbb{C}$ \\ 1 School of Geography and Information Engineering, China University of Geoscience, Wuhan 430074, China; \\ yuwen@cug.edu.cn (Y.C.); wang@cug.edu.cn (L.W.); sqwang@igsnrr.ac.cn (S.W.) \\ 2 Department of Physical Geography and Ecosystem Science, Lund University, 22100 Lund, Sweden; \\ torbern.tagesson@nateko.lu.se \\ 3 State Key Laboratory of Information Engineering in Surveying, Mapping and Remote Sensing, \\ Wuhan University, Wuhan 430079, China; shishuo@whu.edu.cn (S.S.); weigong@whu.edu.cn (W.G.) \\ * Correspondence: sunjia@cug.edu.cn
}

check for updates

Citation: Chen, Y.; Sun, J.; Wang, L.; Shi, S.; Gong, W.; Wang, S.; Tagesson, T. Optimized Estimation of Leaf Mass per Area with a 3D Matrix of Vegetation Indices. Remote Sens. 2021, 13, 3761. https://doi.org/10.3390/ rs13183761

Academic Editors: Jochem Verrelst, Aleixandre Verger, Yelu Zeng and Gaofei Yin

Received: 4 August 2021

Accepted: 15 September 2021

Published: 19 September 2021

Publisher's Note: MDPI stays neutral with regard to jurisdictional claims in published maps and institutional affiliations.

Copyright: (C) 2021 by the authors Licensee MDPI, Basel, Switzerland. This article is an open access article distributed under the terms and conditions of the Creative Commons Attribution (CC BY) license (https:// creativecommons.org/licenses/by/ $4.0 /)$
Abstract: Leaf mass per area (LMA) is a key plant functional trait closely related to leaf biomass. Estimating LMA in fresh leaves remains challenging due to its masked absorption by leaf water in the short-wave infrared region of reflectance. Vegetation indices (VIs) are popular variables used to estimate LMA. However, their physical foundations are not clear and the generalization ability is limited by the training data. In this study, we proposed a hybrid approach by establishing a three-dimensional (3D) VI matrix for LMA estimation. The relationship between LMA and VIs was constructed using PROSPECT-D model simulations. The three-VI space constituting a 3D matrix was divided into cubical cells and LMA values were assigned to each cell. Then, the 3D matrix retrieves LMA through the three VIs calculated from observations. Two 3D matrices with different VIs were established and validated using a second synthetic dataset, and two comprehensive experimental datasets containing more than 1400 samples of 49 plant species. We found that both 3D matrices allowed good assessments of LMA $\left(\mathrm{R}^{2}=0.76\right.$ and $0.78, \mathrm{RMSE}=0.0016 \mathrm{~g} / \mathrm{cm}^{2}$ and $0.0017 \mathrm{~g} / \mathrm{cm}^{2}$, respectively for the pooled datasets), and their results were superior to the corresponding single Vis, 2D matrices, and two machine learning methods established with the same VI combinations.

Keywords: leaf mass per area; vegetation index; PROSPECT-D model; 3D matrix

\section{Introduction}

Leaf biochemical properties are important indicators of changes in ecosystem functions and environment, and are necessary components in dynamic vegetation models [1-3]. Leaf mass per area (LMA), defined as the ratio of dry mass of a leaf to its one-sided surface area, is one of these key plant traits. Closely related to plant growth, LMA is often used in characterizing leaf biomass [4-7]. It also affects plant adaptation, including plant growth strategy and leaf lifespans, and the lower part of the canopy and longer-lived plants usually contain higher LMA [8-11]. At a broader scale, LMA can explain the differences in functional groups and is closely related to environmental stress [12]. Therefore, accurate LMA prediction is of great significance to improve our understanding of the functioning of the biosphere.

Remote sensing methods have been widely used in predicting plant traits for nondestructive and large-scale measurements [3,13-15]. Foliar spectroscopy-based approaches for estimating leaf biochemistry include physical and empirical methods [16-18]. Though LMA is reported to have obvious absorption peaks in shortwave infrared (SWIR) region, its retrieval remains difficult due to the lower absorption coefficient compared with leaf water content $\left(C_{W}\right)$ [19-21]. This can lead to serious ill-posed problems in physics-based LMA inversion [22-24]. To improve its LMA estimation, Féret et al. [25] determined the range of 1700 to $2400 \mathrm{~nm}$ for LMA retrieval through the PROSPECT model. Qiu et al. [4] 
developed a new version of PROSPECT-g to consider the anisotropic scattering within leaves. The physical method has a rigorous mathematical foundation, yet its inversion can be complicated and time-consuming because of the numerous amounts of parameters [26]. Among the empirical methods, fitting relationships to vegetation indices (VIs) are one of the most popular. Several VIs have been developed for LMA estimation [27-29]. They require observations of only a few spectral bands and are very convenient to use. Constructing regression models between vegetation indices (VIs) and leaf physiological traits with machine learning (ML) algorithms have also achieved success [30,31]. Partial least squares regression (PLSR) was used by Serbin et al. [32] to establish a widely applicable LMA prediction model. However, a substantial amount of prior information is needed to train the regression equations, and their quality is found to be restricted by the training data, especially when the model is to be applied on a dataset independent from the training set [25].

In order to combine the benefits of physical methods and VIs, this study proposes a hybrid VI-combination approach for optimizing LMA estimation from leaf reflectance. The relationship between LMA and three VIs constituting a three-dimensional (3D) matrix was established using PROSPECT-D simulations. Six different VIs were used in the construction of two 3D matrices for LMA estimation. Their performance was tested using a second synthetic dataset and two comprehensive experimental datasets against the corresponding single VIs and 2D matrices. This method is expected to precisely retrieve LMA without prior information and has the potential to aid the estimation of other leaf components.

\section{Materials and Methods}

\subsection{Data Description}

\subsubsection{PROSPECT Model}

Based on the plate model [33], the PROSPECT model was developed in 1990 [34] and has been widely used in modeling of radiative transfer in a leaf. PROSPECT-D is the version developed in 2017 and was reported to perform better than previous versions [35]. The input parameters of PROSPECT-D include leaf structure index $(\mathrm{N})$, leaf chlorophyll content $\left(\mathrm{C}_{\mathrm{ab}}\right)$, carotenoid content $\left(\mathrm{C}_{\mathrm{ar}}\right)$, anthocyanin content $\left(\mathrm{C}_{\mathrm{ant}}\right)$, brown pigment content $\left(\mathrm{C}_{\text {brown }}\right)$, leaf water content $\left(\mathrm{C}_{\mathrm{w}}\right)$, and leaf mass per area (LMA). The forward running of the model can generate accurate simulations of leaf hemispherical reflectance and transmittance from $400 \mathrm{~nm}$ to $2500 \mathrm{~nm}$ at a resolution of $1 \mathrm{~nm}$. Leaf chemical traits can be inverted using PROSPECT-D by assigning the component content of the most similar spectrum to the measured electromagnetic spectrum.

\subsubsection{Description of the Synthetic Datasets}

By running the PROSPECT-D model in the forward mode, two synthetic datasets were generated. The model parameters were assumed to have a Gaussian distribution, and their statistical characteristics were listed in Table 1 based on previous studies [20,32]. The model parameters of $C_{a n t h}$ and $C_{\text {brown }}$ were not considered here as they are insensitive to leaf reflectance in the SWIR domain based on sensitivity analysis and therefore set at $0 \mu \mathrm{g} / \mathrm{cm}^{2}[36]$.

Table 1. Distribution characteristics of the leaf parameters used in the PROSPECT-D simulations for generating the synthetic datasets (STD: standard deviation).

\begin{tabular}{ccccc}
\hline Title 1 & Min & Max & Mean & STD \\
\hline $\mathrm{N}$ & 1 & 3.5 & 1.6 & 0.3 \\
$\mathrm{C}_{\mathrm{ab}}\left(\mu \mathrm{g} / \mathrm{cm}^{2}\right)$ & 0 & 110 & 32.81 & 18.87 \\
$\mathrm{C}_{\mathrm{ar}}\left(\mu \mathrm{g} / \mathrm{cm}^{2}\right)$ & 0 & 30 & 8.51 & 3.92 \\
$\mathrm{EWT}\left(\mathrm{g} / \mathrm{cm}^{2}\right)$ & 0 & 0.07 & 0.0115 & 0.007 \\
$\mathrm{LMA}\left(\mathrm{g} / \mathrm{cm}^{2}\right)$ & 0.001 & 0.04 & 0.01 & 0.07 \\
\hline
\end{tabular}


The first synthetic dataset was composed of 200,000 simulations (hereinafter dataset $\mathrm{T})$ for training the 3D matrices. The second synthetic dataset (hereinafter dataset E) with 1000 simulations was generated for evaluating the 3D matrices. Given that synthetic data have a stable distribution feature, further enlarging the size of validation datasets would not greatly affect the quantification of the accuracy of the simulated LMA.

\subsubsection{Description of the Experimental Datasets}

Since both the synthetic training and validation data sets were generated with the same settings in the PROSPECT-D model, they cannot be considered independent. Hence, in order to do a truly independent evaluation, we compiled two experimental datasets. These also take the various realistic factors in actual measurements into account, and validate the inversion results of LMA based on the synthetic T dataset. The first dataset was the Leaf Optical Properties Experiment (LOPEX) dataset [37], which was released by the Joint Research Center of the European Commission in 1993. This dataset consists of 330 leaves from 45 plant species. Leaf reflectance spectra within 400-2500 nm were measured with a spectrophotometer equipped with an integrating sphere. Five corn dry leaves were excluded because the PROSPECT-D model is intended for fresh leaves [35].

The second dataset was collected at Madison, Wisconsin (hereinafter called MA) in the summer of 2016 by the University of Wisconsin Environmental Spectroscopy Laboratory [38]. Leaf reflectance spectra within 350-2500 nm were measured using an ASD FieldSpec 3 instrument with a leaf clip. This dataset contains 1143 leaves of four plant types: grasses, trees, vines, and forbs. The two experimental datasets contain a total of 1468 leaves, representing different leaf internal structures, leaf spectra, and biochemical components. The spectral resolution of the measured leaf reflectance in both datasets was $1 \mathrm{~nm}$.

\subsection{D Matrix Approach for Estimating LMA}

\subsubsection{VIs for Building the 3D Matrices}

As the absorption characteristics of LMA are weak even at its sensitive wavelengths $[20,36]$, LMA estimation using a single VI or physically-based method is often inaccurate [39]. Thus, in the current study, six VIs correlated with LMA were combined in two different 3D matrices using PROSPECT-D simulations to enhance the retrieval of LMA. The VIs selected have been demonstrated to have comparatively good performance by previous studies.

The first 3D matrix is composed of modified simple ratio (MSR), normalized difference (ND), and simple reflectivity (R2300) indices. The MSR index was developed to compensate for leaf surface reflectance [28,40]. The ND index was a commonly used indicator for predicting LMA [27]. As to the R2300 index, leaf reflectance at $2300 \mathrm{~nm}$ is reported to be sensitive to LMA [28]. The expressions of MSR, ND, and R2300 are presented in Table 2.

Table 2. Spectral indices constructing the first 3D matrix.

\begin{tabular}{cccc}
\hline Index & Index ID & Formula & Reference \\
\hline Modified simple ratio-type index & MSR & $\frac{(\text { R2265 - R2400) }}{(\text { R1620 - R2400) }}$ & {$[28,40]$} \\
Normalized difference-type index & ND & $\frac{(\mathrm{R} 1368-\mathrm{R} 1722)}{(\mathrm{R} 1368+\mathrm{R} 1722)}$ & {$[27,39]$} \\
Single reflectivity-type index & R2300 & R2300 & {$[28]$} \\
\hline
\end{tabular}

The second 3D matrix consisted of single reflectivity-type (R1800), modified ND (MND) and difference-type (D) indices. R1800 is based on the SWIR band, being one of the most relevant bands indicating LMA variability [32]. The MND is a more sophisticated index than ND, which has a similar capability of MSR to compensate for leaf surface reflectance $[28,40]$. Previous studies showed that the use of spectral information from 1700 $\mathrm{nm}$ to $2400 \mathrm{~nm}$ was more conducive, improving the accuracy of LMA estimation, and the D index was particularly consistent with this conclusion [25]. The R1800, MND, and D indices are defined in Table 3. 
Table 3. Spectral indices constructing the second 3D matrix.

\begin{tabular}{cccc}
\hline Index & Index ID & Formula & Reference \\
\hline Difference-type index & $\mathrm{D}$ & $\mathrm{R} 2395-\mathrm{R} 2295$ & {$[28]$} \\
Modified normalized & $\mathrm{MND}$ & $\frac{(\mathrm{R} 2285-\mathrm{R} 1335)}{(\mathrm{R} 2285+\mathrm{R} 1335-\mathrm{R} 2400 \times 2)}$ & {$[28,41]$} \\
difference-type index & $\mathrm{R} 1800$ & $\mathrm{R} 1800$ & {$[32]$} \\
\hline Single reflectivity-type index & & & \\
\hline
\end{tabular}

The two 3D matrices contained VIs of similar forms and wavelengths. For instance, wavelengths around $1300 \mathrm{~nm}, 1700 \mathrm{~nm}$, and $2300 \mathrm{~nm}$ were found to be effective for extracting LMA [20].

\subsubsection{Establishment of the $3 \mathrm{D}$ Matrices}

To construct the LMA 3D matrices, we first divided the $\mathrm{VI}_{1}-\mathrm{VI}_{2}-\mathrm{VI}_{3}$ space into several small cells of the same size (Figure 1). Each cell was linked to an LMA value, which corresponded to a small range of the three VI values. Thus, the smaller the size of the cells in the 3D matrix, the more simulations are needed for building up the whole 3D matrix. In the present study, the 3-VI space was partitioned into $100 \times 100 \times 100$ combining both accuracy and efficiency. In this way, two LMA 3D matrices were generated by using the two VI combinations in Section 2.2.1.

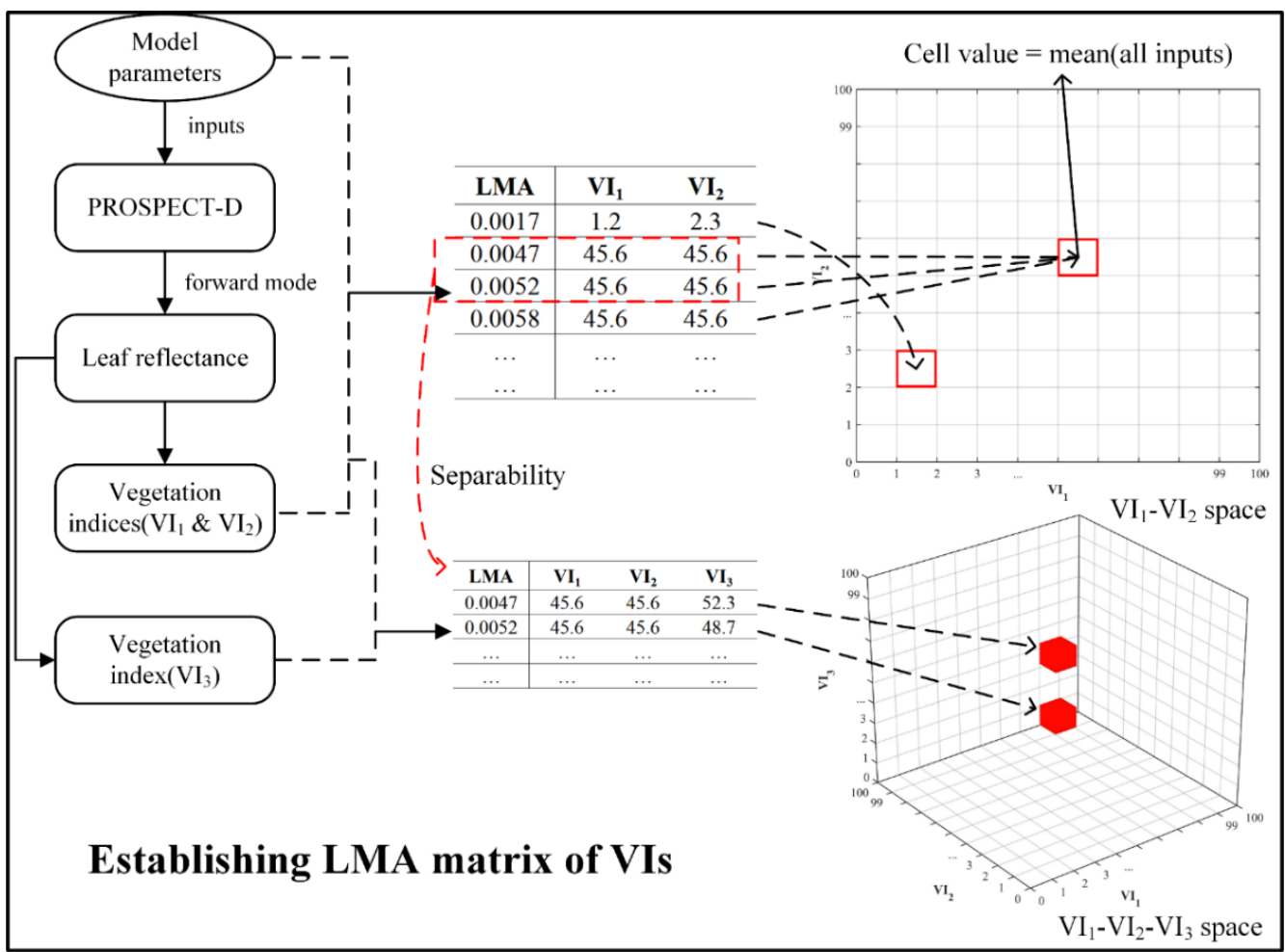

Figure 1. Establishment of the LMA 3D matrix.

The training process of an LMA 3D matrix is as follows. First, for all samples in synthetic dataset $\mathrm{T}$, the three VIs adopted by the 3D matrix were calculated. Second, the 3D domain of each cell in the 3D matrix was determined by dividing the full variation range of each VI by 100. Finally, the corresponding LMA of each sample in synthetic dataset $\mathrm{T}$ was assigned to a specific cell in the 3D matrix, directed by the coordinates of calculated VIs. In cases that different LMA values were mapped to the same cell, their average was considered the final cell value. The process of establishing a 2D matrix follows a similar procedure. The linear regression model of each VI was generated using the 
synthetic dataset T. Furthermore, the standard deviation of each cell in the 3D matrices were established to indicate the uncertainty of the 3D matrices.

\subsubsection{Estimation of the LMA}

After the establishment of a 3D matrix, LMA can be estimated through referring to the three VIs calculated from observations of a sample. The working mode of a 3D matrix includes two cases:

Case 1. Direct retrieval: The three VI values calculated from leaf reflectance are traced back to one cell in the matrix. If the cell has a non-null value, the matrix returns it directly as the LMA value retrieved by the 3D matrix.

Case 2. Indirect retrieval (nearest neighbor retrieval): In some rare cases, the cell directly searched by the matrix is not a number $(\mathrm{NaN})$, and a second retrieval is required. All cells with LMA values nearest to the current cell are identified, and their average is retrieved as the LMA by the 3D matrix.

\subsection{Estimation of LMA through ML Algorithms}

Support vector machine (SVM) is a supervised learning model that is widely used for regression of high-dimensional samples [42]. When it fits linear model in a highdimensional space, it limits the complexity of the model by minimizing the risk of overfitting [43]. PLSR is often used in spectroscopy to handle high predictive collinearity and insufficient observed variables. PLSR can reduce the impact of these circumstances by orthogonalizing the predictor variables [32,44]. In this study, we utilized SVM with linear kernel function and PLSR methods as comparison to estimate LMA. The ML models were parameterized using the VI combinations and the LMA simulations of the synthetic dataset $\mathrm{T}$ (described in Section 2.2.1).

\subsection{Accuracy Evaluation}

Each of the three VIs constituting the 3D matrix can also constitute three 2D matrices. For the evaluation of their performance, both 3D matrices were compared with their 2D versions and single Vis, and the ML methods in terms of estimating LMA using the independent experimental datasets and synthetic $\mathrm{E}$ dataset. The following statistical parameters were used: coefficient of determination $\left(R^{2}\right)$, root mean square error (RMSE), and normalized root mean square error (NRMSE) [45,46]:

$$
\begin{gathered}
\mathrm{R}^{2}=1-\frac{\sum_{i=1}^{n}\left(y_{i}^{\prime}-y_{i}\right)^{2}}{\sum_{i=1}^{n}\left(y^{\prime}{ }_{i}-\bar{y}\right)^{2}} \\
\operatorname{RMSE}=\sqrt{\frac{\sum_{i=1}^{n}\left(y^{\prime}{ }_{i}-y_{i}\right)^{2}}{n}} \\
\operatorname{NRMSE}(\%)=\frac{\mathrm{RMSE}}{y_{\text {max }}-y_{\text {min }}} \cdot 100
\end{gathered}
$$

where $y^{\prime}{ }_{i}$ and $y_{i}$ is the estimated and measured LMA values, respectively; $y_{\max }$ and $y_{\min }$ are the maximum and minimum values of $y_{i}$, respectively; $n$ is the number of measurements, and $i$ is the serial number of the measured LMA.

\section{Results}

\subsection{D Matrices of VIs for LMA}

The distribution of samples in the synthetic dataset $\mathrm{T}$ in the $3 \mathrm{D}$ matrix shows a trend, where most points formed a curved face, with the rest distributed below the surface (Figures 2 and 3). Several LMA iso-surfaces can be observed in both 3D matrices, indicating a progressive trend from the minimum to the maximum. Notably, a converging point existed in both matrices, in which almost all the LMA iso-surfaces converged. The coordinate values of this point were theoretically close to the extreme values of VIs calculated based 
on synthetic dataset T (approximately MSR of 0.4353 , ND of 0.0321 , and R2300 of 0.0201 for MSR-ND-R2300; R1800 of 0.0896, MND of -1 , and D of 0.0078 for R1800-MND-D). The farther away from the converging point, the more obvious the differences between different LMA values were, thereby facilitating LMA inversion.

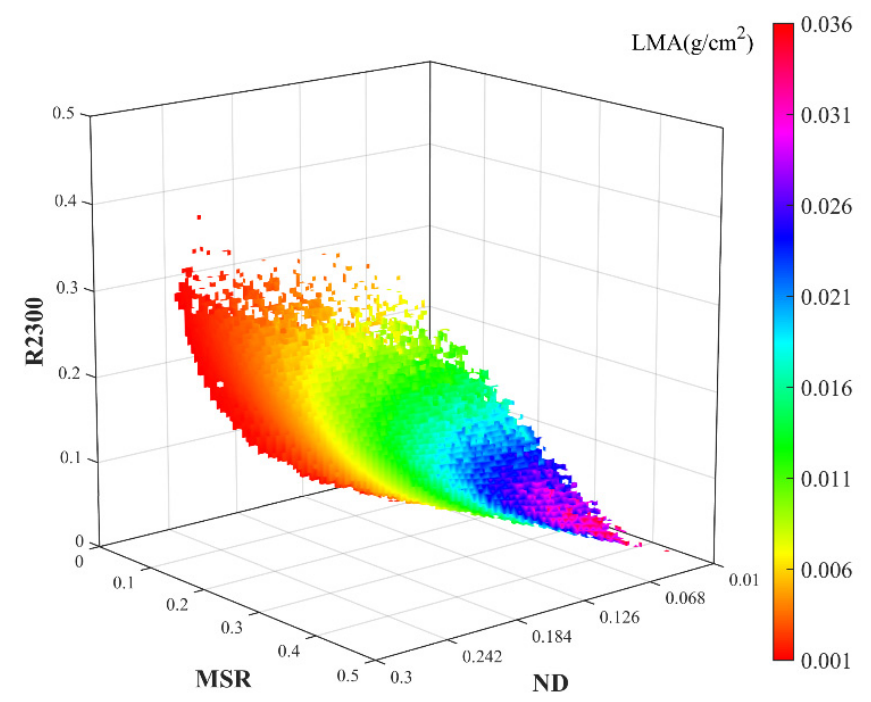

Figure 2. 3D matrix composed of the modified simple ratio (MSR), the normalized difference-type index (ND), and leaf reflectance at $2300 \mathrm{~nm}$ (R2300) using dataset T of 200,000 simulations (the converging point locates around MSR of 0.4353 , ND of 0.0321 , and R2300 of 0.0201 ).

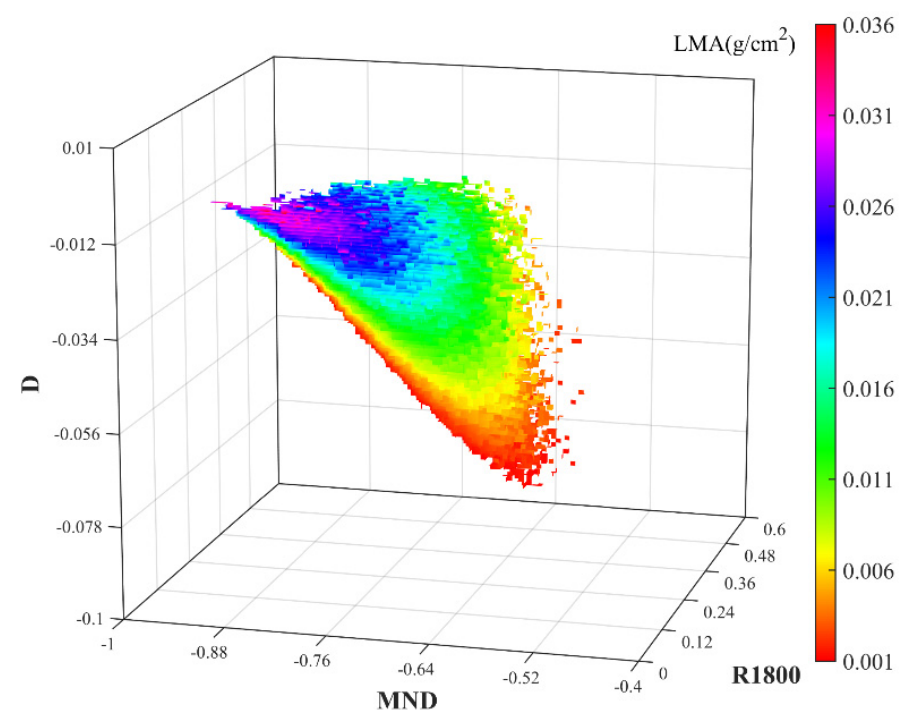

Figure 3. 3D matrix composed of leaf reflectance at $1800 \mathrm{~nm}$ (R1800), the modified normalized difference-type index (MND), and the difference-type index (D) using dataset $\mathrm{T}$ of 200,000 simulations (the converging point locates around R1800 of 0.0896 , MND of -1 , and D of 0.0078 ).

Representing the uncertainty of the two 3D matrices in LMA estimation, two 3D matrices of standard deviation (STD) were calculated (Figures 4 and 5). In these 3D matrices, the farther away from the converging point, the smaller the standard deviation. This indicated that the sensitivity of the 3D matrix to LMA increases from the converging point to the extended direction. Cells with high LMA values in both 3D matrices usually have high STD. Besides, the overall STD of MSR-ND-R2300 was lower than that of R1800MND-D. The average STD of R1800-MND-D $\left(0.003 \mathrm{~g} / \mathrm{cm}^{2}\right)$ was approximately three times that of MSR-ND-R2300 $\left(0.001 \mathrm{~g} / \mathrm{cm}^{2}\right)$. These results showed that MSR-ND-R2300 had a lower uncertainty than R1800-MND-D for LMA estimation. 


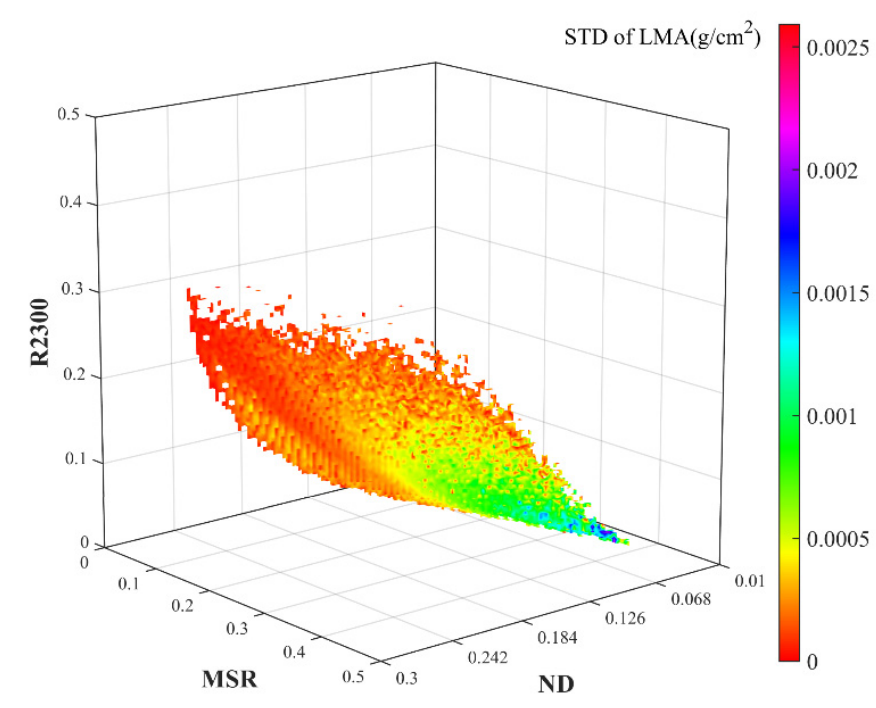

Figure 4. The standard deviation 3D matrix of MSR-ND-R2300.

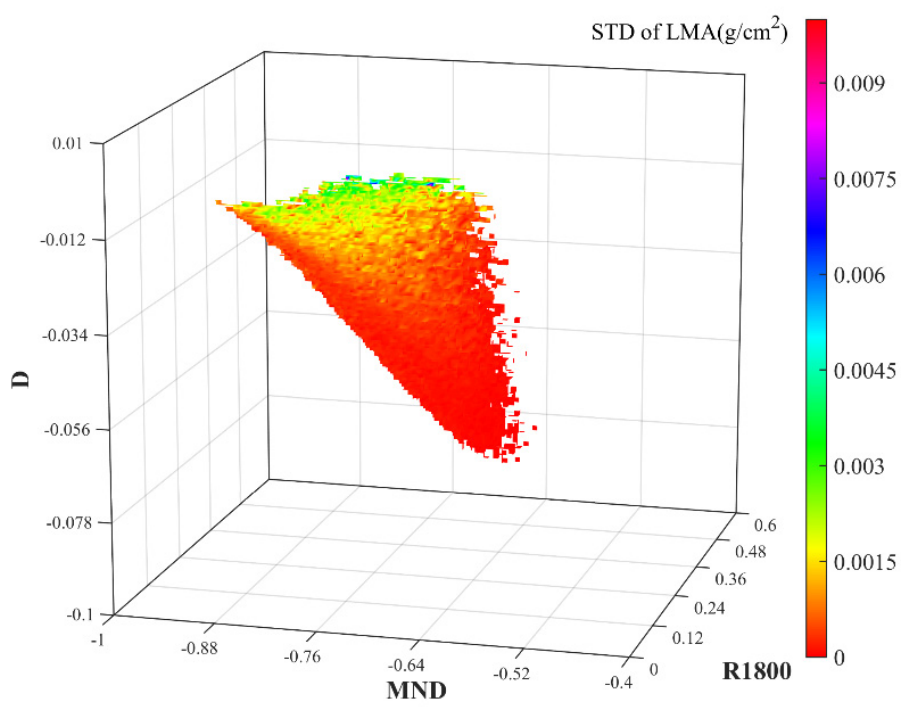

Figure 5. The standard deviation 3D matrix of R1800-MND-D.

\subsection{Evaluation of the LMA Matrices}

\subsubsection{Evaluation against Synthetic Data}

Both 3D matrices provided substantially higher accuracy estimating LMA for the synthetic dataset $\mathrm{E}$ compared to the corresponding estimates of the $2 \mathrm{D}$ matrices and the single VIs (Tables 4 and 5). In most cases, 3D matrices performed better than the 2D matrices, and the 2D matrices performed better than the single VIs. Of all combinations, the matrix MSR-ND-R2300 had the highest accuracy $\left(R^{2}=0.99, R M S E=0.0005 \mathrm{~g} / \mathrm{cm}^{2}\right.$, NRMSE $=1.7 \%$ ). The NRMSE of LMA retrieved by either of the two 3D matrices was less than $2 \%$, indicating that the 3D matrices significantly optimized LMA estimation, and the effects of involving more than three VIs may not be obvious. 
Table 4. Retrieval performances of LMA using MSR-ND-R2300, corresponding 2D matrices and single VIs (the optimal results are indicated in bold).

\begin{tabular}{cccc}
\hline \multirow{2}{*}{ VI or Matrix } & \multicolumn{3}{c}{ Synthetic Dataset E } \\
\cline { 2 - 4 } & $\mathbf{R}^{\mathbf{2}}$ & RMSE (g/cm $\mathbf{~})$ & NRMSE (\%) \\
\hline MSR & 0.71 & 0.0040 & 13.2 \\
ND & 0.85 & 0.0022 & 7.3 \\
R2300 & 0.39 & 0.0044 & 14.6 \\
\hline MSR-ND & 0.91 & 0.0017 & 5.6 \\
MSR-R2300 & 0.93 & 0.0015 & 5.0 \\
ND-R2300 & 0.98 & 0.0008 & 2.6 \\
\hline MSR-ND-R2300 & $\mathbf{0 . 9 9}$ & $\mathbf{0 . 0 0 0 5}$ & $\mathbf{1 . 7}$ \\
\hline
\end{tabular}

Table 5. Retrieval performances of LMA using R1800-MND-D, corresponding 2D matrices, and single VIs (the optimal results are indicated in bold).

\begin{tabular}{cccc}
\hline \multirow{2}{*}{ VI or Matrix } & \multicolumn{3}{c}{ Synthetic Dataset E } \\
\cline { 2 - 4 } & $\mathbf{R}^{\mathbf{2}}$ & RMSE (g/cm $\mathbf{~})$ & NRMSE (\%) \\
\hline R1800 & 0.20 & 0.0051 & 16.9 \\
MND & 0.69 & 0.0032 & 10.6 \\
D & 0.57 & 0.0037 & 12.3 \\
\hline R1800-MND & 0.91 & 0.0017 & 5.6 \\
R1800-D & 0.82 & 0.0024 & 7.9 \\
MND-D & 0.95 & 0.0013 & 4.3 \\
\hline R1800-MND-D & $\mathbf{0 . 9 9}$ & $\mathbf{0 . 0 0 0 6}$ & $\mathbf{2 . 0}$ \\
\hline
\end{tabular}

\subsubsection{Evaluation against the Experimental Datasets}

The retrieval performances of LMA using MSR-ND-R2300, corresponding 2D matrices, single VIs, and ML models were compared against the experimental datasets (Table 6). For both experimental datasets, the MSR-ND-R2300 matrix consistently performed best in estimating LMA. The improvement of the LMA estimation by the MSR-ND-R2300 was more significant on the dataset LOPEX (RMSE decreased by 36\%) than on the MA dataset (RMSE decreased by 5\%). Given the superior performance of the MSR-ND-R2300 on both datasets, it yielded the highest accuracy of LMA estimation on the pooled dataset $\left(\mathrm{R}^{2}=0.78, \mathrm{RMSE}=0.0017 \mathrm{~g} / \mathrm{cm}^{2}, \mathrm{NRMSE}=10.5 \%\right)$. Thus, the matrix of MSR-ND-R2300 was considered a more robust and high-precision method than the relevant 2D matrices, single VIs, and ML algorithms.

The retrieval performances of LMA using R1800-MND-D and corresponding 2D matrices, single VIs, and the two ML models were also compared against the experimental datasets (Table 7). The R1800-MND-D performed best for estimating LMA using the pooled experimental dataset $\left(\mathrm{R}^{2}=0.76\right.$, RMSE $\left.=0.0016 \mathrm{~g} / \mathrm{cm}^{2}, \mathrm{NRMSE}=9.9 \%\right)$. For both experimental datasets, the retrieval of LMA using matrix of R1800-MND-D yielded the highest accuracy (RMSE $=0.0016 \mathrm{~g} / \mathrm{cm}^{2}$ for MA, RMSE $=0.0015 \mathrm{~g} / \mathrm{cm}^{2}$ for LOPEX). To conclude, the matrix of R1800-MND-D is also a superior method for estimating LMA compared with the corresponding 2D matrices, single VIs, and the two ML models. 
Table 6. Corresponding to the MSR-ND-R2300 matrix, the coefficient of determination $\left(\mathrm{R}^{2}\right)$, root mean square error (RMSE, in $\mathrm{g} / \mathrm{cm}^{2}$ ), and normalized RMSE (NRMSE, \%) of the estimated LMA from experimental datasets using the 3D matrix, corresponding 2D matrices, single VIs, support vector machine (SVM), and partial least-squares regression (PLSR) (the optimal results are indicated in bold).

\begin{tabular}{cccccccccc}
\hline \multirow{2}{*}{ VI or Matrix or ML } & \multicolumn{3}{c}{ MA } & \multicolumn{3}{c}{ LOPEX } & \multicolumn{3}{c}{ POOLED } \\
\cline { 2 - 10 } & $\mathbf{R}^{\mathbf{2}}$ & RMSE & NRMSE & $\mathbf{R}^{\mathbf{2}}$ & RMSE & NRMSE & $\mathbf{R}^{\mathbf{2}}$ & RMSE & NRMSE \\
\hline MSR & 0.69 & 0.0030 & 20.1 & 0.45 & 0.0025 & 17.9 & 0.59 & 0.0029 & 17.9 \\
ND & 0.79 & 0.0019 & 12.8 & 0.56 & 0.0025 & 17.9 & 0.68 & 0.0020 & 12.3 \\
R2300 & 0.36 & 0.0024 & 16.1 & 0.14 & 0.0040 & 28.6 & 0.26 & 0.0028 & 17.3 \\
\hline MSR-ND & 0.49 & 0.0030 & 20.1 & 0.41 & 0.0024 & 17.1 & 0.45 & 0.0029 & 17.9 \\
MSR-R2300 & 0.70 & 0.0021 & 14.1 & 0.48 & 0.0019 & 13.6 & 0.62 & 0.0021 & 13.0 \\
ND-R2300 & 0.84 & 0.0023 & 15.4 & 0.73 & 0.0026 & 18.6 & 0.76 & 0.0024 & 14.8 \\
\hline MSR-ND-R2300 & $\mathbf{0 . 8 5}$ & $\mathbf{0 . 0 0 1 8}$ & $\mathbf{1 2 . 1}$ & $\mathbf{0 . 7 4}$ & $\mathbf{0 . 0 0 1 6}$ & $\mathbf{1 1 . 4}$ & $\mathbf{0 . 7 8}$ & $\mathbf{0 . 0 0 1 7}$ & $\mathbf{1 0 . 5}$ \\
SVM & 0.81 & 0.0022 & 14.8 & 0.69 & 0.0023 & 16.4 & 0.73 & 0.0022 & 13.6 \\
PLSR & 0.82 & 0.0020 & 13.5 & 0.69 & 0.0022 & 15.7 & 0.74 & 0.0021 & 13.0 \\
\hline
\end{tabular}

Table 7. Corresponding to R1800-MND-D matrix, the coefficient of determination $\left(\mathrm{R}^{2}\right)$, root mean square error (RMSE, in $\mathrm{g} / \mathrm{cm}^{2}$ ), and normalized RMSE (NRMSE, \%) of the estimated LMA from experimental datasets using 3D matrix, corresponding 2D matrices, single VIs, support vector machine (SVM), and partial least-squares regression (PLSR) (the optimal results are indicated in bold).

\begin{tabular}{|c|c|c|c|c|c|c|c|c|c|}
\hline \multirow{2}{*}{ VI or Matrix or ML } & \multicolumn{3}{|c|}{ MA } & \multicolumn{3}{|c|}{ LOPEX } & \multicolumn{3}{|c|}{ POOLED } \\
\hline & $\mathbf{R}^{2}$ & RMSE & NRMSE & $\mathbf{R}^{2}$ & RMSE & NRMSE & $\mathbf{R}^{2}$ & RMSE & NRMSE \\
\hline R1800 & 0.09 & 0.0041 & 27.5 & 0.03 & 0.0054 & 38.6 & 0.07 & 0.0044 & 27.2 \\
\hline MND & 0.72 & 0.0021 & 14.1 & 0.47 & 0.0022 & 15.7 & 0.62 & 0.0021 & 13.0 \\
\hline D & 0.40 & 0.0019 & 12.8 & 0.28 & 0.0024 & 17.1 & 0.36 & 0.0020 & 12.3 \\
\hline R1800-MND & 0.81 & 0.0019 & 12.8 & 0.61 & 0.0017 & 12.1 & 0.73 & 0.0018 & 11.1 \\
\hline R1800-D & 0.51 & 0.0017 & 11.4 & 0.41 & 0.0020 & 14.3 & 0.48 & 0.0018 & 11.1 \\
\hline MND-D & 0.65 & 0.0022 & 14.8 & 0.46 & 0.0022 & 15.7 & 0.57 & 0.0022 & 13.6 \\
\hline R1800-MND-D & 0.83 & 0.0016 & 10.7 & 0.67 & 0.0015 & 10.7 & 0.76 & 0.0016 & 9.9 \\
\hline SVM & 0.68 & 0.0036 & 24.1 & 0.39 & 0.0038 & 27.1 & 0.57 & 0.0036 & 22.3 \\
\hline PLSR & 0.66 & 0.0031 & 20.7 & 0.37 & 0.0036 & 25.7 & 0.55 & 0.0032 & 19.8 \\
\hline
\end{tabular}

Comparing the two 3D matrices, MSR-ND-R2300 had higher $\mathrm{R}^{2}$ (0.85 for MA, 0.74 for LOPEX, and 0.78 for pooled dataset, Figure $6 \mathrm{a}, \mathrm{c}, \mathrm{e}$ in all experimental datasets, whereas R1800-MND-D achieved lower RMSE $\left(0.0016 \mathrm{~g} / \mathrm{cm}^{2}\right.$ for MA, $0.0015 \mathrm{~g} / \mathrm{cm}^{2}$ for LOPEX, and $0.0016 \mathrm{~g} / \mathrm{cm}^{2}$ for pooled dataset, Figure $6 \mathrm{~b}$,d,f. Moreover, the estimation bias of R1800MND-D for a few samples with LMA around $0.005 \mathrm{~g} / \mathrm{cm}^{2}$ was relatively large, which may lead to the decrease of $R^{2}$. Nevertheless, the RMSE of LMA estimation using the matrix of R1800-MND-D was still lower than that using MSR-ND-R2300. Consequently, the 3D matrix of R1800-MND-D was considered more promising than MSR-ND-R2300 for estimating LMA. 
MA

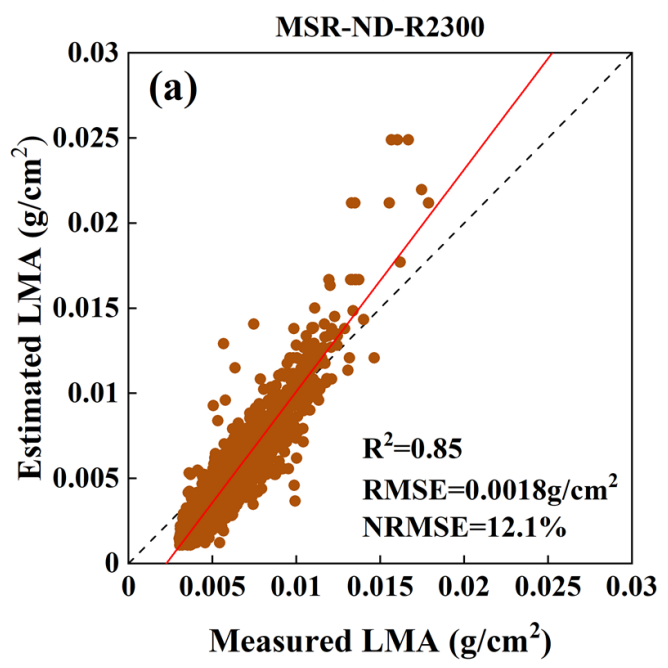

LOPEX

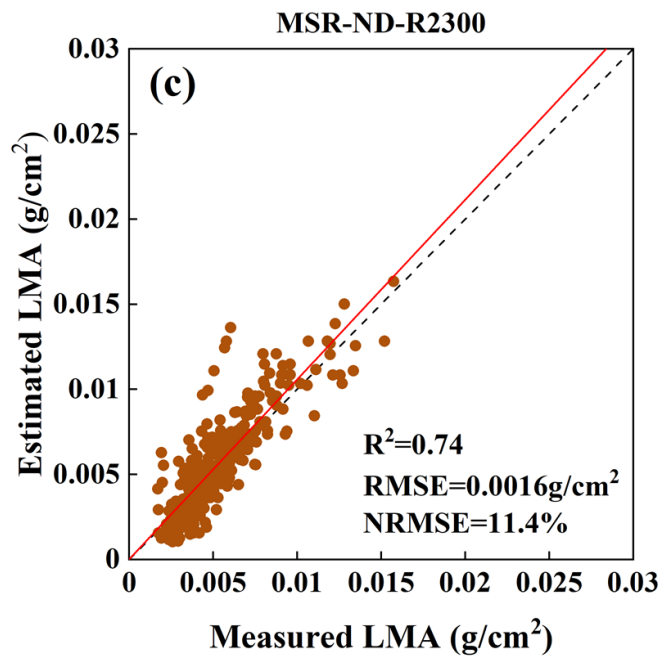

POOLED

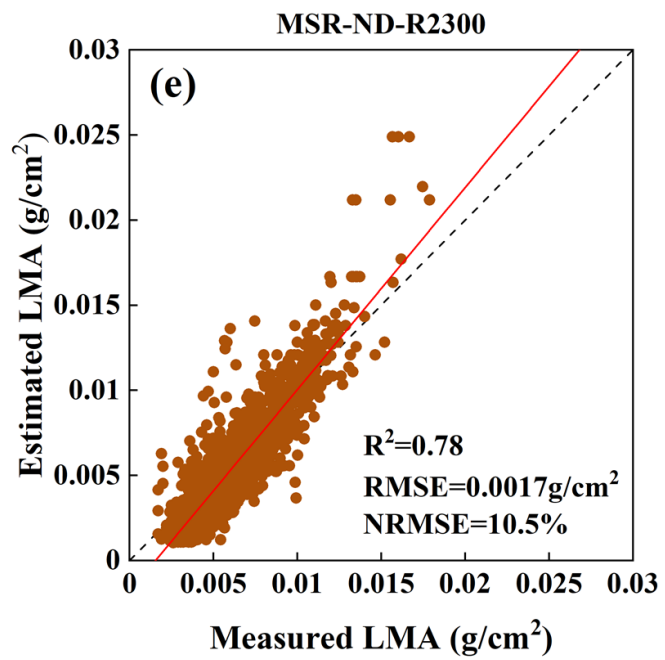

MA

R1800-MND-D

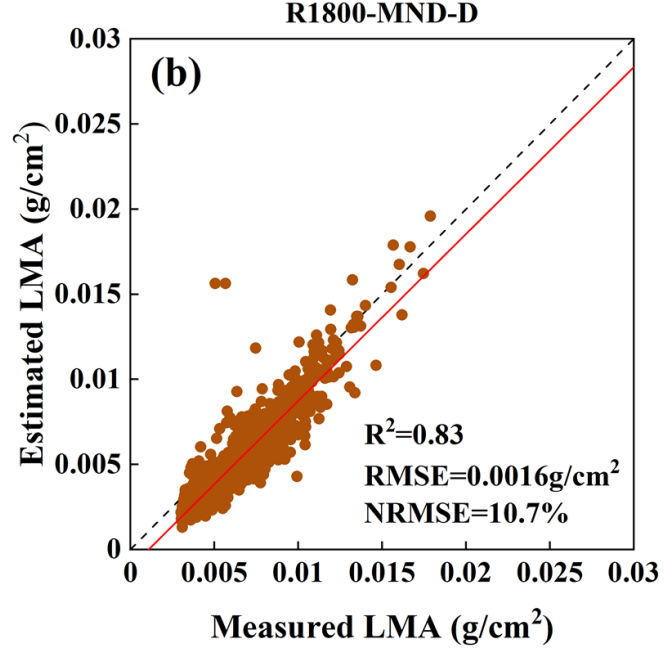

LOPEX

R1800-MND-D

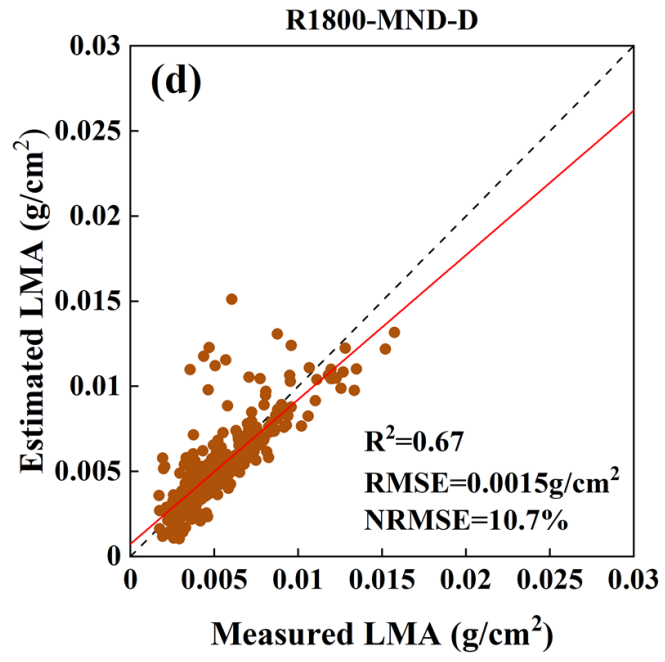

POOLED

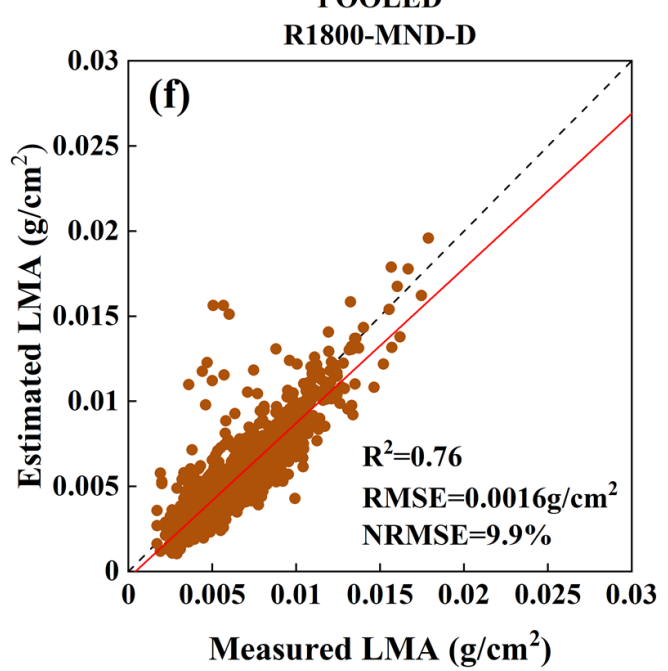

Figure 6. Estimated versus measured LMA based on matrix MSR-ND-R2300 (a,c,e), and R1800-MND$\mathrm{D}(\mathbf{b}, \mathbf{d}, \mathbf{f})$ using experimental datasets LOPEX, MA, and POOLED. 


\section{Discussion}

\subsection{Improvements over Traditional VIs}

Traditional methods for estimating LMA with a single VI commonly use two or several spectral bands related to LMA, and the regression is relatively simple to implement. Nevertheless, as light absorption of LMA is relatively weak and often masked by $\mathrm{C}_{\mathrm{w}}$ in its sensitive bands, the detection of variations in LMA by VIs was limited [39]. The 3D matrix proposed in this study can effectively strengthen the relationship between VIs and LMA, and thus facilitate the retrieval of LMA. The range of LMA in the 3D matrices established in this study was between 0.001 and $0.036 \mathrm{~g} / \mathrm{cm}^{2}$ (Figures 2 and 3), which covered the range of most vegetation species and growing stages according to the TRY database [47] and previous researches [32,48]. In addition, these 3D matrices had achieved good accuracy when estimating LMA on all the validation datasets (Tables 4-7). The especially high accuracy obtained based on synthetic dataset was partly due to that the same Gaussian distribution used in generating synthetic datasets $\mathrm{G}$ and $\mathrm{T}$, and that random and systematic noises were not considered. Yet it proved that the three dimensions were adequate for LMA estimation. Using the 3D matrix improved LMA retrieval compared with any single corresponding VI because inversion is based on similarity of the values of multiple VIs rather than an inaccurate regression relationship susceptible to $C_{W}$ absorption interference.

In addition, our results showed that the proposed method has superior performance compared with the hybrid models based on SVM and PLSR approaches (Tables 6 and 7). We suggested that this method can be applied to indicate LMA when no prior measurements are available. The 3D matrix works very similarly to a lookup table (LUT). The minor difference between the proposed method and the standard LUT with VIs is that the LUT is generated by partitioning the ranges of LMA and other parameters, and then obtaining the corresponding VIs. The 3D matrix, by contrast, is generated by partitioning the ranges of the three VIs, and then the samples with different LMAs are distributed in the matrix. Those samples in the same cell were averaged. Besides, the 3D matrix holds advantages in manifesting a visible and clearer structure of the distribution of the VIs and LMA.

The estimation results of LMA through 3D matrix in this study were also compared with previous reports. Féret et al. [25] used an optimal spectral domain to invert LMA with the PROSPECT model with an RMSE of $0.002 \mathrm{~g} / \mathrm{cm}^{2}$ using the LOPEX dataset. Wu et al. [49] adopted the spectral invariants theory at the leaf level. The inversion accuracy of LMA was $0.0018 \mathrm{~g} / \mathrm{cm}^{2}$ (RMSE) using the same dataset. Validation using LOPEX showed that our method had a slightly higher inversion accuracy $\left(\operatorname{RMSE}=0.0015 \mathrm{~g} / \mathrm{cm}^{2}\right)$.

\subsection{Impact of VI Selection in 3D Matrix Construction}

Two factors that greatly affect the performance of a VI-based matrix are the sensitivity and structure of the VIs. VIs that are sensitive to a parameter of interest or confounding parameters can be combined in the form of a matrix for the improvement of the estimation of this parameter. Selecting VIs sensitive to the parameter of interest is easy to understand, whereas involving VIs sensitive to confounding factors can help alleviate the influence of these factors. Given that the contribution of $\mathrm{C}_{\mathrm{ab}}$ and LAI is hard to differentiate on the canopy scale, $\mathrm{Xu}$ et al. [50] proposed the use of two VIs sensitive to LAI and $\mathrm{C}_{\mathrm{ab}}$ in generating a matrix to decrease the influence of LAI and were then able to improve the accuracy of the model predictions. In the case of LMA, although $\mathrm{C}_{\mathrm{W}}$ affects the detection of the spectral signals of LMA in the SWIR domain, combining VIs related to LMA and $\mathrm{C}_{\mathrm{W}}$ would not result in the same degree of improvement in LMA estimation according to our prior experiments (not shown here). This is due to that the correlation between $\mathrm{C}_{\mathrm{ab}}$ and LAI is strong, while that between LMA and $\mathrm{C}_{\mathrm{w}}$ is much poorer [27]. As a result, a $\mathrm{C}_{\mathrm{W}}$-sensitive $\mathrm{VI}$, while acting as an axis of the matrix, does not assist retrieval of LMA because it has little contribution to LMA differentiation. The results in this study showed that a 3D matrix based on VIs related to LMA yields a high accuracy for LMA estimation, indirectly making up the absorption of LMA. This 3D matrix-based method can potentially 
be applied to invert other leaf parameters, particularly those with weak light absorption features, such as leaf carotenoid content.

In this study, we made no specific restrictions on the types of VIs constituting the 3D matrices, showing that a broad range of VI types can be used in generating a 3D matrix. In future studies, the redundancy of spectral information in selected VIs may be a factor to consider. The VIs of LMA containing bands with low correlations are expected to improve LMA estimation.

\subsection{Sources of Error and Further Development of the 3D Matrix Approach}

Although the 3D matrix-based approach optimizes the LMA estimations, uncertainty exists in three aspects: (1) inaccuracy of the PROSPECT model; (2) the included Vis, and (3) $\mathrm{NaN}$ existed in the 3D matrix. The PROSPECT model assumes the specific absorption coefficient of LMA as the integration of the optical influences of various organic constituents, which may lead to inaccuracies [25]. Additionally, PROSPECT can be inaccurate in describing leaf surface features, such as surface roughness [34]. As a synthetic dataset simulated by the PROSPECT model was used, these uncertainties were propagated when establishing the 3D matrix. Given that here the range of biochemical parameters adopted to generate the synthetic dataset was determined by integrating TRY database and other comprehensive studies, the 3D matrices established in this study hold good generalization ability. However, for specific vegetation types or growth phases, their performance may not be optimal. Using prior information in adjusting the ranges and distributions of biochemical parameters and the relationships between parameters during a 3D matrix establishment can help reduce uncertainty.

Uncertainty also stems from the inherent limitations of VIs, for disparate LMA levels may be misclassified to the same cell because they had similar spectral characteristics within the three VIs. This error may be difficult to eliminate completely because VIs cannot fully reflect variations in LMA. Still, in this respect, the 3D matrix has a lower degree of uncertainty than a 2D one because the third VI corrects some misallocation of the LMA into cells. However, the performance of some 2D matrices on the experimental datasets was inferior to that of single VIs, which may be caused by the interaction between VIs.

Finally, the 3D matrices contained NaN (Figures 2 and 3). The main reason is that some combinations of VI values represented by cells do not exist in real leaf samples, and these cells are theoretically NaN. In addition, the possible inadequacy of PROSPECT model simulations may result in $\mathrm{NaN}$ in some cells. In the inversion process, when the cells with $\mathrm{NaN}$ were matched, the estimation was based on the average of the nearest cells with non-values, which may result in errors.

The results in Section 3.1 showed that the average STD of cells in MSR-ND-R2300 was lower than that in R1800-MND-D, which reflected a theoretically lower uncertainty of the former 3D matrix. However, when estimating LMA from both experimental datasets, the RMSE obtained by MSR-ND-R2300 was higher than that of R1800-MND-D (Section 3.2). The synthetic dataset $\mathrm{E}$ with the same configuration can detect the training accuracy of the $3 D$ matrix, with higher $R^{2}$ often accompanied by smaller errors, thus the average STD of MSR-ND-R2300 was relatively lower. The utilization of synthetic data set may introduce bias to the 3D matrix when applied in experimental datasets. Therefore, the $\mathrm{R}^{2}$ of the two 3D matrices from experimental datasets was therefore consistent with the STD matrices, while the RMSE was not.

This study proposed a novel method for LMA estimation at leaf scale, and the problem of atmospheric absorption could thereby be ignored. However, this could be a serious problem in airborne and satellite imagery applications [51], as it often leads to the weakening or unavailability of some effective reflection features [52]. For instance, VIs with bands covering the spectral region of high-water vapor absorption (such as $1800 \mathrm{~nm}$ and $2400 \mathrm{~nm}$ ) should be avoided. Currently, several VIs for LMA inversion at the canopy scale have been developed $[28,53,54]$, providing a promising basis for the development of a 3D LMA matrix at the canopy scale. The 3D matrix suitable for the canopy scale needs to 
be further investigated. Additionally, the PROSPECT model needs to be coupled with a canopy reflectance model, and the signal-to-noise ratio of VIs at the canopy scale should be considered.

\section{Conclusions}

The remote sensing of LMA is often challenging due to its lower light absorption coefficient compared with $C_{W}$ in the SWIR region. Thus, this study developed a novel approach for optimizing LMA estimation using a 3D VI matrix based on PROSPECT-D simulations. The results showed that compared with the corresponding single VIs and 2D matrices, the 3D matrix improved the estimation of LMA effectively. Compared with the machine learning models constructed using the same VI combinations, the 3D matrices estimate LMA more accurately. Between the two 3D matrices, R1800-MND-D achieved slightly better comprehensive performance than MSR-ND-R2300, with a lower RMSE for both experimental datasets. Given the physical principle used in constructing the 3D matrix, and that little prior information was involved in calibrating the models, the 3D matrix shows high potential for a stronger generalization capability. The proposed method can provide valuable guidance for reflecting vegetation growth, development stages, as well as physiological response to environmental stresses.

Author Contributions: Conceptualization, J.S.; methodology, J.S. and Y.C.; software, Y.C.; validation, J.S. and Y.C.; formal analysis, J.S. and Y.C.; investigation, J.S. and Y.C.; resources, J.S. and Y.C.; data curation, J.S. and Y.C.; writing—original draft preparation, J.S. and Y.C.; writing-review and editing, J.S., Y.C., T.T., L.W., S.S., W.G. and S.W.; visualization, Y.C.; supervision, J.S.; project administration, J.S.; funding acquisition, J.S. All authors have read and agreed to the published version of the manuscript.

Funding: This research was funded by the National Key R\&D Program of China (2018YFB0504500); National Natural Science Foundation of China (42001314); Open Research Fund of the State Laboratory of Information Engineering in Surveying, Mapping, and Remote Sensing, Wuhan University (grant number 20R02), and Fundamental Research Funds for the Central Universities, China University of Geosciences, Wuhan (grant number 111-G1323520290). T.T. was funded by SNSA (Dnr 96/16) and the EU-Aid-funded CASSECS project.

Data Availability Statement: All data used in this manuscript are publicly available through EcoSIS spectral database, including LOPEX (https:/ / ecosis.org/package/leaf-optical-propertiesexperiment-database--lopex93-) and MA (https:/ / ecosis.org/package/7433af7d-fbbd-4617-8df4-4 d892f0d4357 (accessed on 1 January 2019)).

Acknowledgments: We thank the open access to the LOPEX and MA datasets, as well as the PROSPECT-D model.

Conflicts of Interest: The authors declare no conflict of interest. Authors are aware of and comply with best practices in publication ethics specifically about authorship (avoidance of guest authorship), dual submission, manipulation of figures, competing interests, and compliance with policies on research ethics. The authors adhere to publication requirements that submitted work is original and has not been published elsewhere in any language. Additionally, all procedures performed in studies involving human participants were by the ethical standards of the institutional and/or national research committee and with the 1964 Helsinki Declaration and its later amendments or comparable ethical standards. All procedures performed in this study involving animals were following the ethical standards of the institution or practice at which the studies were conducted.

\section{References}

1. Asner, G.P.; Martin, R.E. Spectranomics: Emerging science and conservation opportunities at the interface of biodiversity and remote sensing. Glob. Ecol. Conserv. 2016, 8, 212-219. [CrossRef]

2. Schimel, D.; Pavlick, R.; Fisher, J.; Asner, G.P.; Saatchi, S.; Townsend, P.; Miller, C.; Frankenberg, C.; Hibbard, K.; Cox, P. Observing terrestrial ecosystems and the carbon cycle from space. Glob. Chang. Biol. 2015, 21, 1762-1776. [CrossRef]

3. Zhang, Y.; Migliavacca, M.; Penuelas, J.; Ju, W. Advances in hyperspectral remote sensing of vegetation traits and functions. Remote Sens. Environ. 2020, 252, 112121. [CrossRef] 
4. Qiu, F.; Chen, J.M.; Ju, W.; Wang, J.; Zhang, Q.; Fang, M. Improving the PROSPECT Model. to Consider Anisotropic Scattering of Leaf Internal Materials and Its Use for Retrieving Leaf Biomass in Fresh Leaves. IEEE Trans. Geosci. Remote Sens. 2018, 56, 3119-3136. [CrossRef]

5. Westoby, M. A leaf-height-seed (LHS) plant ecology strategy scheme. Plant Soil 1998, 199, 213-227. [CrossRef]

6. Wright, I.J.; Reich, P.; Westoby, M.; Ackerly, D.D.; Baruch, Z.; Bongers, F.; Cavender-Bares, J.; Chapin, T.; Cornelissen, J.H.; Diemer, M. The worldwide leaf economics spectrum. Nature 2004, 428, 821-827. [CrossRef]

7. Violle, C.; Navas, M.-L.; Vile, D.; Kazakou, E.; Fortunel, C.; Hummel, I.; Garnier, E. Let the concept of trait be functional! Oikos 2007, 116, 882-892. [CrossRef]

8. Adler, P.B.; Salguero-Gomez, R.; Compagnoni, A.; Hsu, J.S.; Ray-Mukherjee, J.; Mbeau-Ache, C.; Franco, M. Functional traits explain variation in plant life history strategies. Proc. Natl. Acad. Sci. USA 2014, 111, 740-745. [CrossRef]

9. John, G.P.; Scoffoni, C.; Buckley, T.N.; Villar, R.; Poorter, H.; Sack, L. The anatomical and compositional basis of leaf mass per area. Ecol. Lett. 2017, 20, 412-425. [CrossRef]

10. Reich, P.B.; Cornelissen, H. The world-wide 'fast-slow' plant economics spectrum: A traits manifesto. J. Ecol. 2014, 102, $275-301$. [CrossRef]

11. Feilhauer, H.; Schmid, T.; Faude, U.; Sánchez-Carrillo, S.; Cirujano, S. Are remotely sensed traits suitable for ecological analysis? A case study of long-term drought effects on leaf mass per area of wetland vegetation. Ecol. Indic. 2018, 88, 232-240. [CrossRef]

12. Poorter, H.; Niinemets, U.; Poorter, L.; Wright, I.J.; Villar, R. Causes and consequences of variation in leaf mass per area (LMA): A meta-analysis. New Phytol. 2009, 182, 565-588. [CrossRef]

13. Weiss, M.; Jacob, F.; Duveiller, G. Remote sensing for agricultural applications: A meta-review. Remote Sens. Environ. 2019, 236, 111402. [CrossRef]

14. Houborg, R.; Fisher, J.; Skidmore, A. Advances in remote sensing of vegetation function and traits. Int. J. Appl. Earth Obs. Geoinf. 2015, 43, 1-6. [CrossRef]

15. Moreno-Martínez, Á.; Camps-Valls, G.; Kattge, J.; Robinson, N.; Reichstein, M.; van Bodegom, P.; Kramer, K.; Cornelissen, J.H.C.; Reich, P.; Bahn, M.; et al. A methodology to derive global maps of leaf traits using remote sensing and climate data. Remote Sens. Environ. 2018, 218, 69-88. [CrossRef]

16. Asner, G.P.; Martin, R.E.; Tupayachi, R.; Emerson, R.; Martinez, P.; Sinca, F.; Powell, G.V.; Wright, S.J.; Lugo, A.E. Taxonomy and remote sensing of leaf mass per area (LMA) in humid tropical forests. Ecol. Appl. 2011, 21, 85-98. [CrossRef]

17. Colombo, R.; Meroni, M.; Marchesi, A.; Busetto, L.; Rossini, M.; Giardino, C.; Panigada, C. Estimation of leaf and canopy water content in poplar plantations by means of hyperspectral indices and inverse modeling. Remote Sens. Environ. 2008, 112, 1820-1834 [CrossRef]

18. Feilhauer, H.; Asner, G.P.; Martin, R.E. Multi-method ensemble selection of spectral bands related to leaf biochemistry. Remote Sens. Environ. 2015, 164, 57-65. [CrossRef]

19. Hinojo-Hinojo, C.; Goulden, M.L. Plant Traits Help Explain the Tight Relationship between Vegetation Indices and Gross Primary Production. Remote Sens. 2020, 12, 1405. [CrossRef]

20. Sun, J.; Shi, S.; Yang, J.; Gong, W.; Qiu, F.; Wang, L.; Du, L.; Chen, B. Wavelength selection of the multispectral lidar system for estimating leaf chlorophyll and water contents through the PROSPECT model. Agric. For. Meteorol. 2019, 266, 43-52. [CrossRef]

21. Yang, B.; He, Y.; Chen, W. A simple method for estimation of leaf dry matter content in fresh leaves using leaf scattering albedo. Glob. Ecol. Conserv. 2020, 23, e01201. [CrossRef]

22. Conejo, E.; Frangi, J.-P.; De Rosny, G. Neural network implementation for a reversal procedure for water and dry matter estimation on plant leaves using selected LED wavelengths. Appl. Opt. 2015, 54, 5453-5460. [CrossRef]

23. Curran, P.J.; Dungan, J.L.; Peterson, D.L. Estimating the foliar biochemical concentration of leaves with reflectance spectrometry: Testing the Kokaly and Clark methodologies. Remote Sens. Environ. 2001, 76, 349-359. [CrossRef]

24. Jacquemoud, S.; Ustin, S.; Verdebout, J.; Schmuck, G.; Andreoli, G.; Hosgood, B. Estimating leaf biochemistry using the PROSPECT leaf optical properties model. Remote Sens. Environ. 1996, 56, 194-202. [CrossRef]

25. Féret, J.-B.; le Maire, G.; Jay, S.; Berveiller, D.; Bendoula, R.; Hmimina, G.; Cheraiet, A.; Oliveira, J.C.; Ponzoni, F.J.; Solanki, T.; et al. Estimating leaf mass per area and equivalent water thickness based on leaf optical properties: Potential and limitations of physical modeling and machine learning. Remote Sens. Environ. 2018, 231, 110959. [CrossRef]

26. Quan, X.; He, B.; Yebra, M.; Yin, C.; Liao, Z.; Li, X. Retrieval of forest fuel moisture content using a coupled radiative transfer model. Environ. Model. Softw. 2017, 95, 290-302. [CrossRef]

27. Féret, J.-B.; François, C.; Gitelson, A.; Asner, G.P.; Barry, K.M.; Panigada, C.; Richardson, A.D.; Jacquemoud, S. Optimizing spectral indices and chemometric analysis of leaf chemical properties using radiative transfer modeling. Remote Sens. Environ. 2011, 115, 2742-2750. [CrossRef]

28. Le Maire, G.; François, C.; Soudani, K.; Berveiller, D.; Pontailler, J.; Breda, N.; Genet, H.; Davi, H.; Dufrene, E. Calibration and validation of hyperspectral indices for the estimation of broadleaved forest leaf chlorophyll content, leaf mass per area, leaf area index and leaf canopy biomass. Remote Sens. Environ. 2008, 112, 3846-3864. [CrossRef]

29. Wang, Q.; Li, P. Hyperspectral indices for estimating leaf biochemical properties in temperate deciduous forests: Comparison of simulated and measured reflectance data sets. Ecol. Indic. 2012, 14, 56-65. [CrossRef]

30. Gitelson, A.A.; Keydan, G.P.; Merzlyak, M.N. Threeband model for noninvasive estimation of chlorophyll, carotenoids, and anthocyanin contents in higher plant leaves. Geophys. Res. Lett. 2006, 33. [CrossRef] 
31. Main, R.; Cho, M.A.; Mathieu, R.; O'Kennedy, M.M.; Ramoelo, A.; Koch, S. An investigation into robust spectral indices for leaf chlorophyll estimation. ISPRS J. Photogramm. Remote Sens. 2011, 66, 751-761. [CrossRef]

32. Serbin, S.P.; Wu, J.; Ely, K.S.; Kruger, E.L.; Townsend, P.A.; Meng, R.; Wolfe, B.T.; Chlus, A.; Wang, Z.; Rogers, A. From the Arctic to the tropics: Multibiome prediction of leaf mass per area using leaf reflectance. New Phytol. 2019, 224, 1557-1568. [CrossRef]

33. Allen, W.A.; Gausman, H.W.; Richardson, A.J.; Thomas, J.R. Interaction of Isotropic Light with a Compact Plant Leaf. J. Opt. Soc. Am. 1969, 59, 1376-1379. [CrossRef]

34. Jacquemoud, S.; Baret, F. PROSPECT: A model of leaf optical properties spectra. Remote Sens. Environ. 1990, 34, 75-91. [CrossRef]

35. Féret, J.-B.; Gitelson, A.; Noble, S.; Jacquemoud, S. PROSPECT-D: Towards modeling leaf optical properties through a complete lifecycle. Remote Sens. Environ. 2017, 193, 204-215. [CrossRef]

36. Yang, J.; Yang, S.; Zhang, Y.; Shi, S.; Du, L. Improving characteristic band selection in leaf biochemical property estimation considering interrelations among biochemical parameters based on the PROSPECT-D model. Opt. Express 2021, 29, 400-414. [CrossRef] [PubMed]

37. Hosgood, B.; Jacquemoud, S.; Andreoli, G.; Verdebout, J.; Pedrini, G.; Schmuck, G. Leaf Optical Properties Experiment 93 (LOPEX93); Report EUR 16095; Joint Research Centre, Institute for Remote Sensing Applications: Ispra, Italy, 1995.

38. Chlus, A. Ecological Spectral Information System. Leaf Level Spectra and LMA for a Set of Trees, Forbs, Vines and Grasses Collected in Madison, WI. Data Set. 2016. Available online: http:/ / ecosis.org (accessed on 1 January 2019).

39. Cheng, T.; Rivard, B.; Sánchez-Azofeifa, A.G.; Féret, J.-B.; Jacquemoud, S.; Ustin, S.L. Deriving leaf mass per area (LMA) from foliar reflectance across a variety of plant species using continuous wavelet analysis. ISPRS J. Photogramm. Remote Sens. 2014, 87, 28-38. [CrossRef]

40. Sims, D.A.; Gamon, J.A. Relationships between leaf pigment content and spectral reflectance across a wide range of species, leaf structures and developmental stages. Remote Sens. Environ. 2002, 81, 337-354. [CrossRef]

41. Le Maire, G.; François, C.; Dufrêne, E. Towards universal broad leaf chlorophyll indices using PROSPECT simulated database and hyperspectral reflectance measurements. Remote Sens. Environ. 2004, 89, 1-28. [CrossRef]

42. Cortes, C.; Vapnik, V. Support-vector networks. Mach. Learn. 1995, 20, 273-297. [CrossRef]

43. Sun, J.; Yang, J.; Shi, S.; Chen, B.; Du, L.; Gong, W.; Song, S. Estimating Rice Leaf Nitrogen Concentration: Influence of Regression Algorithms Based on Passive and Active Leaf Reflectance. Remote Sens. 2017, 9, 951. [CrossRef]

44. Geladi, P.; Kowalski, B.R. Partial least-squares regression: A tutorial. Anal. Chim. Acta 1986, 185, 1-17. [CrossRef]

45. Koirala, B.; Zahiri, Z.; Scheunders, P. A Machine Learning Framework for Estimating Leaf Biochemical Parameters From Its Spectral Reflectance and Transmission Measurements. IEEE Trans. Geosci. Remote Sens. 2020, 58, 7393-7405. [CrossRef]

46. Sun, J.; Shi, S.; Yang, J.; Du, L.; Gong, W.; Chen, B.; Song, S. Analyzing the performance of PROSPECT model inversion based on different spectral information for leaf biochemical properties retrieval. ISPRS J. Photogramm. Remote Sens. 2018, 135, 74-83. [CrossRef]

47. Kattge, J.; Diaz, S.; Lavorel, S.; Prentice, I.C.; Leadley, P.; Bönisch, G.; Garnier, E.; Westoby, M.; Reich, P.B.; Wright, I.J. TRY—A global database of plant traits. Glob. Chang. Biol. 2011, 17, 2905-2935. [CrossRef]

48. Paula, S.; Pausas, J.G. Leaf traits and resprouting ability in the Mediterranean basin. Funct. Ecol. 2006, 20, 941-947. [CrossRef]

49. Wu, S.; Zeng, Y.; Hao, D.; Liu, Q.; Li, J.; Chen, X.; Asrar, G.R.; Yin, G.; Wen, J.; Yang, B.; et al. Quantifying leaf optical properties with spectral invariants theory. Remote Sens. Environ. 2020, 253, 112131. [CrossRef]

50. Xu, M.; Liu, R.; Chen, J.M.; Liu, Y.; Shang, R.; Ju, W.; Wu, C.; Huang, W. Retrieving leaf chlorophyll content using a matrix-based vegetation index combination approach. Remote Sens. Environ. 2019, 224, 60-73. [CrossRef]

51. Sun, J.; Xu, F.; Cervone, G.; Gervais, M.; Wauthier, C.; Salvador, M. Automatic atmospheric correction for shortwave hyperspectral remote sensing data using a time-dependent deep neural network. ISPRS J. Photogramm. Remote Sens. 2021, 174, 117-131. [CrossRef]

52. Gao, B.-C.; Davis, C.; Goetz, A. A review of atmospheric correction techniques for hyperspectral remote sensing of land surfaces and ocean color. IEEE Int. Symp. Geosci. Remote Sens. 2006, 1979-1981. [CrossRef]

53. Ali, A.M.; Darvishzadeh, R.; Skidmore, A.; Duren, I.v. Effects of Canopy Structural Variables on Retrieval of Leaf Dry Matter Content and Specific Leaf Area From Remotely Sensed Data. IEEE J. Sel. Top. Appl. Earth Obs. Remote Sens. 2016, 9, 898-909. [CrossRef]

54. Cheng, T.; Song, R.; Li, D.; Zhou, K.; Zheng, H.; Yao, X.; Tian, Y.; Cao, W.; Zhu, Y. Spectroscopic Estimation of Biomass in Canopy Components of Paddy Rice Using Dry Matter and Chlorophyll Indices. Remote Sens. 2017, 9, 319. [CrossRef] 